Uluslararası Tarım ve Yaban Hayatı Bilimleri Dergisi
hittp://dergipark.org.tr/jijaws

Araştırma Makalesi

\title{
Farklı Lokasyonların Lavandin (Lavandula $\times$ intermedia Emeric ex Loisel.)'de Uçucu Yağ Oranı ve Kimyasal Kompozisyonu Üzerine Etkisi
}

\author{
Duran Katar $^{1 *}$, Mustafa Can ${ }^{2}$, Nimet Katar ${ }^{2}$ \\ ${ }^{1}$ Eskişehir Osmangazi Üniversitesi, Ziraat Fakültesi, Tarla Bitkileri Bölümü, Eskişehir \\ ${ }^{2}$ Eskişehir Osmangazi Üniversitesi, Fen Bilimleri Enstitüsü, Eskişehir \\ Geliş tarihi (Received): $30.04 .2020 \quad$ Kabul tarihi (Accepted): 15.07.2020
}

\section{Anahtar kelimeler: \\ Melez lavanta, Lavandulax intermedia, farklı lokasyonlar, uçucu yağ oranı ve bileşenleri}

\author{
*Sorumlu yazar \\ durankatar6060@gmail.com
}

Özet. Bu araştırmanın amacı lavandin (Lavandula $\times$ intermedia) bitkisinde farklı (Afyon, Eskişehir, Isparta ve Uşak) lokasyonların uçucu yağ oranı ve uçucu yağın kimyasal kompozisyonu üzerine etkisini belirlemektir. Bitkiler 4 farkıı lokasyonda yetiştirilmiştir. 48 saat boyunca $35^{\circ} \mathrm{C}$ 'de kurutulmuş olan çiçek örnekleri, 210 dakika süreyle hidro-distilasyona tabi tutularak uçucu yağ oranları belirlenmiştir. Örneklerin uçucu yağ bileşenleri GC/MS cihazı kullanılarak tespit edilmiştir. Farklı lokasyonlardan elde edilen uçucu yağ oranları sırasıyla: \%5.93 (Afyon), \%5.63 (Eskişehir), \%7.80 (Isparta) ve \%6.57 (Uşak)'dır. GC/MS cihazında yapılan analiz sonuçlarına göre, uçucu yağ örneklerinde 40 farklı bileşen tespit edilmiştir. Analiz edilen uçucu yağ örneklerinin ana bileşenleri linalool (\%41.34-53.10), linalil asetat (\%1.83-23.54), kafur (\%4.487.60) ve 1,8-sineol (\%1.95-6.27)'dur. Sonuçlar; farklı lokasyonların melez lavantanın (Lavandula $\times$ intermedia) uçucu yağ oranı ve kimyasal komposizyonu üzerinde etkili olduğunu göstermiştir.

\section{Effect of Different Locations on Essential Oil Content and Chemical Composition in Lavandin (Lavandula $\times$ intermedia Emeric ex Loisel.)}

\footnotetext{
Keywords:

Lavandin, Lavandula $\times$ intermedia, different locations, content and composition of essential oil

\begin{abstract}
The purpose of this research was to determine the effect of different locations (Afyon, Eskişehir, Isparta and Uşak) on the essential oil content and the chemical composition of the essential oil in lavandin (Lavandula $\times$ intermedia) plant. The plants were cultivated in 4 different locations. Flower samples dried at $35^{\circ} \mathrm{C}$ for 48 hours were subjected to hydro-distillation for 210 minutes to determine essential oil contents. The essential oil compositions of the samples were identified with GC/MS. The contents of essential oil in different locations were 5.93\% (Afyon), 5.63\% (Eskişehir), 7.80\% (Isparta) and 6.57\% (Uşak), respectively. According to the results of analysis with GC/MS, 40 different compounds were detected in essential oil samples. The main components of the analyzed essential oil samples were linalool (41.34-53.10\%), linalyl acetate (1.83-23.54\%), camphor (4.48-7.60\%) and 1,8-cineole (1.95-6.27\%). Results showed that different locations were effective on essential oil content and chemical composition of essential oil in lavandin (Lavandula $\times$ intermedia) plant.
\end{abstract}




\section{GíRiş}

Lavanta bitkisi, Lamiaceae/Labiatae familyasına ait önemli bir uçucu yağ bitkisidir (Beus, 2006; Baydar, 2013, Erbaş ve ark., 2017). Lamiaceae familyası ülkemizde 46 cins ve 571 tür ile temsil edilmektedir (Kara ve ark., 2014). Lavanta bitkisi Akdeniz havzasının kayalık ve kireçli bölgelerinde doğal olarak yayılış göstermekle birlikte Kuzey Afrika, Avrupa ve Batı Hindistan'da da doğal olarak yetişmektedir (Erbaş ve ark., 2017). Lavandula cinsinin dünyanın farklı bölgelerinde doğal olarak yayılış gösteren 48 türü bulunmaktadır. Bu türler, uçucu yağlarının kimyasal kompozisyonu ve gelişme formları bakımından farklılık gösteren yüzlerce genotipe sahiptir (Beus, 2006). Fransa, Bulgaristan, İtalya, Yunanistan, İngiltere, ABD, Avusturya, Rusya ve Kuzey Afrika'nın birçok ülkesinde yoğun olarak kültürü/yetiştiriciliği yapılmaktadır. Ülkemizde ise yaklaşık 3200 da alanda lavanta (Lavandula hybrida) tarımı yapılmaktadır (Erbaş ve ark., 2017).

Lamiaceae familyasına ait olan lavanta bitkisinin dünyada kültürü yapılan 5 önemli türü bulunmaktadır (Beus, 2006). Bunlardan biri olan Lavandin (Lavandula hybrida), Akdeniz kuşağında özellikle kalkerli alanlarda yayılış göstermekte, $70-80 \mathrm{~cm}$ kadar boylanabilen çalımsı bir form oluşturmaktadır. Bu tür, İngiliz lavantasına (Lavandula angustifolia) göre uçucu yağı daha düşük kalitede, ancak yüksek oranda uçucu yağ içermektedir. Lavanta ayrıca oluşturduğu taç yapısı ve yaydığı güzel koku nedeniyle önemli bir süs ve çit bitkisidir (Whiriskey ve McCarthy, 2006; Karık ve ark., 2017). Özellikle Lavandula dentata ve Lavandula stoechas türleri süs ve çit bitkisi olarak kullanılmaktadır (Beus, 2006; Karık ve ark., 2017).

Lavanta uçucu yağında bulunan en önemli iki bileşen linalil asetat (\%20-60) ve linalool (\%20-35)'dur (Hui ve ark., 2010). Özellikle linalil asetat, lavanta yağının kalitesini belirleyen en önemli bileşendir. Çünkü lavanta uçucu yağına karakteristik özelliğini kazandıran linalil asetat olup, bu bileşenin uçucu yağın içerisindeki oranının yüksek olması yağa kozmetik ve özellikle parfümeri endüstrisinde kullanımı açısından değer kazandırmaktadır (Başer, 1993; Sönmez ve ark., 2018). Kafur ve 1,8-sineol bakımından zengin lavanta yağları ise ilaç ve insektisit endüstrisi için değerlidir (Baydar, 2013). 1,8-sineol oranı yüksek olan lavanta yağları genelde uyarıcı ve balgam söktürücü olarak kullanılırken, kafur oranı yüksek olan lavanta yağları ise özellikle böcek kovucu/kaçırıcı olarak kullanılmaktadır (Baydar, 2010). Ilaç endüstrisinde veya halk hekimliğinde linalool oranı yüksek olan lavanta uçucu yağları ise daha çok sinirleri yatıştııcı, uykusuzluk ve yorgunluk giderici (doğal sakinleştirici) olarak kullanılmaktadır (Sönmez ve ark., 2018). Dünyada ticari anlamda en fazla üretilen lavanta yağı, melez bir tür olan Lavandula hybrida (L. angustifolia x L. latifolia)'dan elde edilen lavandin yağıdır (Beus, 2006; Karık ve ark., 2017). Avrupa farmakopesine göre parfüm üretiminde kullanılacak lavanta uçucu yağının linalil asetat oranı en az \%35 olması ve kafurun üst sınııının \%1.2 olması istenmektedir. Lavender yağını, lavandin yağından ayıran temel özellik ise lavender yağında kafur bulunmaması veya belirtilen sınırların altında olmasıdır (Karık ve ark., 2017). Yine, ISO 3515:2002 standardına göre lavanta yağında linalool ve linalil asetatın \%25'in üzerinde olması, kafur ve limonen'in $\% 0.5$ 'in altında olması, terpinen 4-ol'un \%2-6 arasında olması ve $\alpha$-terpinen'in ise \%1'den az olması istenmektedir (Kara ve Baydar, 2014). Lavandin bitkisi üzerinde yürütülen birçok çalışma uçucu yağ oranı ve yağın kompozisyonu üzerinde üretimde kullanılan materyallerin genetik yapısının, üretimin yapıldığı bölgelerin ekolojik koşullarının ve yetiştiricilik uygulamalarının etkili olduğunu ortaya koymuştur (Biesiada ve ark., 2008; Kara ve Baydar, 2014; Karık ve ark., 2017; Erbaş ve ark., 2017; Sönmez ve ark., 2018). Lavandin bitkisi kullanılarak farklı lokasyonlarda yürütülen çalışmalar lokasyonların elde edilen kuru çiçeklerdeki uçucu yağ oranı ve uçucu yağın kompozisyonu üzerinde önemli değişikliklere neden olduğunu göstermiştir (Kara ve Baydar, 2014; Karık ve ark., 2017; Gülşen, 2017, Erbaş ve ark., 2017).

Çalışmanın amacı Afyon, Eskişehir, Isparta ve Uşak lokasyonlarının lavandin bitkisinin uçucu yağ oranı ve uçucu yağ kompozisyonu üzerindeki etkisini tespit etmektir.

\section{MATERYAL VE METOT}

Araştırmada bitki materyali olarak Isparta'nın Keçiborlu İlçesi/Kuyucak Köyünden temin edilen lavandin (Lavandula x intermedia cv. Super) çeşidine ait fideler kullanılmıştır. Çalışmanın yürütüldüğü Afyon (rakım:1010 m), Eskişehir (rakım 792 m), Isparta (rakım 1049 m) ve Uşak (rakım 907 m) illerinin uzun yıllar ve 2019 yılına ait iklim verileri Çizelge 1'de verilmiştir. Çiçek hasadının yapıldığı 2019 yılına ait toplam yıllık yağışlar sırasıyla 402.3, 426.8, 453.5 ve $414.3 \mathrm{~mm}$ olarak tespit edilirken, uzun yıllara ait değerler ise 443.5, 374.2, 570.2 ve $557.6 \mathrm{~mm}$ olarak tespit edilmiştir. Buradan da görüldüğü gibi 2019 yılı için en düşük yağış alan ilimiz Afyon ile en yüksek yağışı alan ilimiz olan Isparta arasında \%12.73 yağış farkı tespit edilmiştir. Eskişehir ile Uşak ili yağışlarının diğer illere kıyasla birbirine daha yakın olduğu görülmüştür. Uzun yılların toplam yağış miktarları dikkate alındığında ise Afyon $(443.5 \mathrm{~mm}$ ) ve Eskişehir $(374.2 \mathrm{~mm}$ ) lokasyonlarının değerleri birbirine daha yakın iken Isparta (570.2 mm) 

Etkisi

ve Uşak (557.6 mm) lokasyonlarının değerlerinin birbirine daha yakın olduğu belirlenmiştir. Çalışmanın yürütüldüğü illerin tümü genel olarak yarı kurak iklim bölgesinde yer almaktadır. 2019 yılı için illerin sırasıyla ortalama sıcaklıkları ise $12.7,12.8,13.3$ ve $13.6{ }^{\circ} \mathrm{C}$ olarak tespit edilmiştir. Ortalama yıllık sıcaklıklar dikkate alındığında Afyon ve Eskişehir illeri birbirine daha yakınken diğer taraftan Isparta ve Uşak illerinin birbirine daha yakın olduğu görülmektedir. Uzun yılların ortalama sıcaklıkları dikkate alındığında ise Afyon (11.2 $\left.{ }^{\circ} \mathrm{C}\right)$ ve Eskişehir $\left(11.2{ }^{\circ} \mathrm{C}\right)$ lokasyonlarının değerleri birbirine daha yakın iken Isparta $\left(12.2^{\circ} \mathrm{C}\right)$ ve Uşak $\left(12.4{ }^{\circ} \mathrm{C}\right)$ lokasyonlarının değerlerinin birbirlerine daha yakın olduğu belirlenmiştir.

Çizelge 1. Deneme lokasyonlarına ait iklim verileri.

Table 1. Meteorological data of the experiment locations.

\begin{tabular}{|c|c|c|c|c|c|c|c|c|c|c|c|c|c|c|c|c|}
\hline \multirow{3}{*}{ Aylar } & \multicolumn{8}{|c|}{$\begin{array}{c}\text { Toplam Yağış } \\
\text { (mm) }\end{array}$} & \multicolumn{8}{|c|}{$\begin{array}{c}\text { Ortalama Sicaklık } \\
\left({ }^{\circ} \mathrm{C}\right)\end{array}$} \\
\hline & \multicolumn{4}{|c|}{2019 Yılı } & \multicolumn{4}{|c|}{ Uzun Yıllar } & \multicolumn{4}{|c|}{2019 Yılı } & \multicolumn{4}{|c|}{ Uzun Yıllar } \\
\hline & L1 & $\mathbf{L 2}$ & L3 & L4 & L1 & $\mathbf{L 2}$ & L3 & L4 & L1 & $\mathbf{L 2}$ & L3 & L4 & L1 & $\mathbf{L} 2$ & L3 & L4 \\
\hline Ocak & 58.9 & 40.3 & 97.0 & 87.9 & 44.6 & 41.4 & 81.0 & 73.4 & 1.6 & 1.7 & 2.5 & 1.6 & 0.2 & -0.0 & 1.7 & 2.2 \\
\hline Şubat & 36.9 & 51.5 & 55.4 & 17.3 & 39.6 & 35.8 & 67.6 & 66.7 & 4.0 & 4.1 & 4.4 & 5.4 & 1.7 & 1.6 & 2.9 & 3.2 \\
\hline Mart & 11.1 & 13.3 & 40.3 & 20.8 & 44.7 & 36.9 & 59.0 & 58.0 & 6.8 & 7.3 & 7.4 & 7.8 & 5.2 & 5.3 & 5.9 & 6.1 \\
\hline Nisan & 56.3 & 38.6 & 50.8 & 40.1 & 45.8 & 37.2 & 52.4 & 50.9 & 9.5 & 10.2 & 9.9 & 10.5 & 10.3 & 10.6 & 10.7 & 10.8 \\
\hline Mayıs & 44.1 & 30.3 & 34.2 & 36.9 & 54.9 & 45.4 & 56.6 & 48.0 & 16.7 & 17.4 & 16.8 & 16.7 & 15.0 & 15.4 & 15.4 & 15.5 \\
\hline Haziran & 78.4 & 57.5 & 53.3 & 37.3 & 40.6 & 36.0 & 34.2 & 27.2 & 20.5 & 21.1 & 20.7 & 20.9 & 18.9 & 19.2 & 19.8 & 19.9 \\
\hline Temmuz & 29.1 & 17.4 & 9.5 & 8.9 & 22.4 & 14.6 & 16.1 & 16.5 & 21.9 & 21.8 & 23.3 & 22.8 & 22.1 & 21.8 & 23.3 & 23.3 \\
\hline Ağustos & 4.5 & 2.9 & 2.7 & 0.4 & 13.5 & 7.9 & 14.1 & 12.6 & 22.8 & 22.7 & 24.4 & 24.4 & 22.0 & 21.8 & 23.2 & 23.4 \\
\hline Eylül & 2.7 & 6.6 & 26.5 & 22.1 & 21.5 & 15.3 & 18.7 & 18.6 & 19.4 & 18.8 & 20.0 & 19.4 & 17.7 & 17.7 & 18.8 & 19.1 \\
\hline Ekim & 11.1 & 69.9 & 9.9 & 6.4 & 35.2 & 25.2 & 38.3 & 42.2 & 15.4 & 15.2 & 15.7 & 16.6 & 12.4 & 12.3 & 13.3 & 13.6 \\
\hline Kasım & 11.7 & 22.4 & 28.6 & 47.9 & 33.6 & 30.4 & 45.0 & 58.9 & 10.1 & 9.9 & 9.7 & 11.6 & 6.9 & 7.0 & 7.8 & 8.2 \\
\hline Aralık & 57.5 & 76.1 & 45.3 & 88.3 & 47.1 & 48.1 & 87.2 & 84.6 & 3.5 & 3.3 & 4.6 & 5.5 & 2.3 & 2.2 & 3.5 & 4.1 \\
\hline Toplam & 402.3 & 426.8 & 453.5 & 414.3 & 443.5 & 374.2 & 570.2 & 557.6 & - & - & - & - & - & - & - & - \\
\hline Ortalama & - & - & - & - & - & - & - & - & 12.7 & 12.8 & 13.3 & 13.6 & 11.2 & 11.2 & 12.2 & 12.4 \\
\hline
\end{tabular}

Kaynak: Meteoroloji Genel Müdürlüğü (L1:Afyon, L2: Eskişehir, L3: Isparta, L4:Uşak).

Çalışma lokasyonlarına ait toprakların özelliklerini belirlemek amacıyla alınan örnekler üzerinde yapılan analizlerin sonuçları Çizelge 2'de verilmiştir. Tüm lokasyonların topraklarının tekstür sınıfı killi-tınlıdır. Lokasyonların toprak pH değerleri 7.55-8.01 arasında değişmiş olup, lokasyon toprakları hafif alkali bir durum göstermiştir. Organik madde içerikleri ise \%1.01-4.18 arasında değişmektedir. Uşak ilinin toprak örneğinin organik madde içeriği diğer illere kıyasla daha yüksek bulunmuştur. Diğer illerin organik madde içeriği ise yetersiz düzeydedir. Yararlanılabilir potasyum ve fosfor düzeyleri sırasıyla $241-289 \mathrm{~kg} \mathrm{da}^{-1}$ ve $3.3-4.8 \mathrm{~kg} \mathrm{da}^{-1}$ arasında değişmiştir. Kireç oranları \%19.02-24.03 arasında değişim göstermiştir. Toprakların elektriksel iletkenlik (EC) değerleri $\left(0.019-0.030 \mathrm{dS} \mathrm{m}^{-1}\right)$ dikkate alındığında ise toprakların tuzluluk probleminin olmadığı belirlenmiştir.

Çizelge 2. Deneme lokasyonlarına ait toprakların bazı fiziksel ve kimyasal özellikleri. Table 2. Physical and chemical characteristics of soil in experiment locations.

\begin{tabular}{|c|c|c|c|c|c|c|c|c|}
\hline Lokasyon & Tekstür & $\begin{array}{c}\text { Toplam } \\
\text { Kireç (\%) }\end{array}$ & $\begin{array}{c}E C \\
\left(\mathrm{dS} \mathrm{m}^{-1}\right)\end{array}$ & $\begin{array}{c}\text { Azot } \\
(\%)\end{array}$ & $\begin{array}{c}\text { Fosfor } \\
\left(\mathrm{kg} \mathrm{da}^{-1}\right)\end{array}$ & $\begin{array}{c}\text { Potasyum } \\
\left(\mathbf{k g ~ d a}^{-1}\right)\end{array}$ & $\mathbf{p H}$ & $\begin{array}{c}\text { Organik } \\
\text { Madde (\%) }\end{array}$ \\
\hline Afyon & Killi-Tınlı & 19.54 & 0.019 & 0.12 & 3.3 & 241 & 7.68 & 1.01 \\
\hline Eskişehir & Killi-Tınlı & 20.76 & 0.022 & 0.22 & 3.7 & 258 & 7.55 & 1.67 \\
\hline Isparta & Killi-Tınlı & 24.03 & 0.030 & 0.19 & 3.5 & 275 & 8.01 & 1.51 \\
\hline Uşak & Killi-Tınlı & 19.02 & 0.020 & 0.21 & 4.8 & 289 & 7.73 & 4.18 \\
\hline
\end{tabular}

Toprak analizleri Eskişehir Orman Toprak ve Ekoloji Araştırmaları Enstitüsü Müdürlüğü laboratuvarında yapılmıştır.

Deneme Isparta'nın Keçiborlu İlçesi/Kuyucak Köyünden temin edilen lavandin (Lavandula $x$ intermedia) bitkisine ait fideler kullanılarak Afyonkarahisar Tıbbi ve Aromatik Bitkiler Merkezi, Eskişehir Orman Fidanlık Müdürlüğü, Isparta'nın Keçiborlu İlçesi/Kuyucak Köyü ve Uşak Ulubey ilçesi İnay köyü arazilerinde sırasıyla 11.05.2016, 14.05.2016, 18.05 .2016 ve 20.05.2016 tarihlerinde kurulmuştur. Plantasyon oluşturmak için fideler 1.5 $\mathrm{m}$ sıra arası ve $1 \mathrm{~m}$ sıra üzeri olacak şekilde dikilmiştir (Kara ve Baydar. 2014). Deneme tesadüf blokları deneme desenine göre 3 tekerrürlü olarak kurulmuştur. Her parselde 4 sıra bitki bulunmakta olup, 6 x $5 \mathrm{~m}=30 \mathrm{~m}^{2}$ alana sahiptir. Parsellerin yabancı ot mücadelesi mekanik yöntemlerle yapılmıştır. Parsellere ilave bir sulama yapılmamıştır. Her parselden kenardaki birer sıra ve sıra uçlarından birer bitki kenar tesiri olarak bırakılmıştır. Dört yaşındaki parsellerden Eskişehir ve Uşak lokasyonlarında 08.07.2019 tarihinde Afyon ve Isparta lokasyonlarında ise 15.07.2019 tarihinde bitkilerin \%50'sinin çiçek açtığı dönemde ve gün içerisinde saat 15:00'de hasat edilmiş 
olan taze saplı çiçekler araştırmada materyal olarak kullanılmıştır. Hasat edilmiş olan çiçekli sap örnekleri 48 saat süreyle etüvde $35^{\circ} \mathrm{C}$ sıcaklıkta kurutulmuştur. Kurutulmuş olan bu çiçekli sap örneklerinde çiçekler uçucu yağ distilasyonu için saplarından ayrılmıştır. Kurutulmuş ve saplarından ayrılmış olan çiçek örneklerinin uçucu yağ oranları Eskişehir Osmangazi Üniversitesi Ziraat Fakültesi Tarla Bitkileri Bölümü tıbbi bitkiler laboratuvarında su distilasyonu yöntemiyle belirlenmiştir. Uçucu yağların distilasyonu için ayıklanmış ve kurutulmuş $100 \mathrm{~g}$ kuru çiçek örnekleri 2000 ml'lik balonlara yerleştirildikten sonra 1000 ml saf su eklenerek 3.5 saat boyunca distilasyon işlemi gerçekleştirilmiştir. Distilasyon işlemi tamamlandıktan sonra clevenger aparatının dereceli kısmından yağ miktarı okunarak \% olarak belirlenmiştir. Clevenger cihazından alınan uçucu yağlar bileşenlere bakılacağı zamana kadar 3-4 ${ }^{\circ} \mathrm{C}$ sıcaklıktaki buzdolabında saklanmıştır.

Uçucu yağların bileşenleri çalışma koşulları aşağıda verilen GC/MS cihazıyla Batı Akdeniz Tarımsal Araştırma Enstitüsü Müdürlüğü/Tıbbi Araştırmalar Merkezi Laboratuvar'ında belirlenmiştir. Örnekler analiz edilmek üzere 1:100 oranında hekzan ile seyreltilmiştir. Örneklerin uçucu yağ bileşen analizi GC/GC-MS (Gaz kromatografisi (Agilent 7890A)-kütle detektör (Agilent 5975C) cihazı ile kapiler kolon (HP InnowaxCapillary; 60.0 m x 0.25 mm x $0.25 \mu \mathrm{m}$ ) kullanılarak gerçekleştirilmiştir. Analizde taşıyıcı gaz olarak $0.8 \mathrm{ml} / \mathrm{dk}$ akış hızında helyum kullanılmış. örnekler cihaza $1 \mu \mathrm{l}$ olarak 40:1 split oranı ile enjekte edilmiştir. Enjektör sıcaklığı $250^{\circ} \mathrm{C}^{\prime}$ de tutulmuş. kolon sıcaklık programı $60^{\circ} \mathrm{C}$ (10 dakika). $60^{\circ} \mathrm{C}^{\prime}$ den $250^{\circ} \mathrm{C}$ ye $20^{\circ} \mathrm{C}$ /dakika ve $250^{\circ} \mathrm{C}$ (10.5 dakika) olacak şekilde ayarlanmıştır. Bu sıcaklık programı doğrultusunda toplam analiz süresi 30 dakika olmuştur. Kütle detektörü için tarama aralığı (m/z) 35-450 atomik kütle ünitesi ve elektron bombardımanı iyonizasyonu 70 eV kullanılmıştır. Uçucu yağın bileşenlerinin teşhisinde ise WILEY ve OIL ADAMS kütüphanelerinin verileri esas alınmıştır. Sonuçların bileşen yüzdeleri FID dedektör kullanılarak bileşenlerin teşhisi ise MS dedektör kullanılarak yapılmıştır.

Uçucu yağ oranlarına ait veriler SPSS paket programı kullanılarak tesadüf blokları deneme desenine göre varyans analizine tabi tutularak incelenen özelliklerin önemlilik düzeyleri belirlenmiştir. Önemli çıkan ortalama değerler arasındaki farklar Tukey (Tukey's Honest Significant Difference test) testi ile karşılaştırılmıştır.

\section{BULGULAR VE TARTIŞMA}

Bilindiği gibi aromatik bitkilerde ürünün kalitesini belirleyen en önemli kriter drog olarak kullanılacak bitki kısmının içermiş olduğu uçucu yağ oranıdır (Baydar ve ark., 2013; Dudas ve ark., 2013). Hatta bitkilerin hangi organlarının ürün olarak değerlendirileceğine karar verilirken dikkate alınan en önemli kriter de yine farklı organların içerdiği uçucu yağ oranları olmaktadır (Telci ve ark., 2006; Baydar ve ark., 2013). Aromatik bitkilerin farmakopelerde drog olarak kabul edilmesi ve ilaç olarak kullanılabilmesi için ise içereceği asgari uçucu yağ oranları belirtilmekte ve bu oranların altında uçucu yağ içeren drogların ilaç olarak kullanılmasına izin verilmemektedir (Telci, 2005; Baydar, 2013). Aynı şekilde ürünün ekonomik değerinin belirlenmesinde de içermiş olduğu uçucu yağın oranı önemli bir faktör olarak göz önünde tutulmaktadır (Mammadov, 2014; Karık ve ark., 2017). Bu da aromatik bitkilerin üreticisine kazandıracağı gelirin belirlenmesinde ürünün uçucu yağ içeriğinin önemini göstermektedir. Tüm bunlar dikkate alındığında aromatik bitkilerin içerdiği uçucu yağın oranında değişikliğe neden olan faktörlerin çok iyi bilinmesinin ve bu faktörlerin uçucu yağın oranını pozitif yönde etkileyecek şekilde yönetilmesinin ne kadar büyük öneme sahip olduğu görülmektedir (Katar ve ark., 2018; Tursun ve Telci, 2020). Yürütülen çalışmalar, aromatik bitkilerin uçucu yağ oranları üzerinde üretimde kullanılan bitki materyalinin sahip olduğu kalıtsal yapının, üretimin yapıldığı bölgenin ekolojik koşullarının ve kullanılan üretim tekniklerinin etkili olduğunu ortaya koymuştur (Mumivand ve ark., 2011; Kevseroğlu, 2014; Katar ve ark., 2019; Katar ve Aytaç, 2019; Tursun ve Telci, 2020).

Dört farklı lokasyonda yetiştirilen lavandin (Lavandula $x$ intermedia) çiçeklerinin uçucu yağ oranları lokasyonlardan önemli $(p<0.01)$ düzeyde etkilenmiştir. Lokasyonların ortalaması olarak lavandinde uçucu yağ oranı \%6.48 olarak tespit edilmiştir. Çalışmanın yürütüldüğü lokasyonlara bağlı olarak uçucu yağ oranları \%5.637.80 arasında değişmiş olup bu da lokasyonların uçucu yağ oranı üzerinde \%38.54 oranında bir değişime neden olduğunu göstermiştir. En yüksek uçucu yağ oranı değeri Isparta/Keçiborlu/Kuyucak lokasyonunda tespit edilirken, en düşük değer ise Eskişehir lokasyonundan elde edilmiştir. Afyon, Eskişehir ve Uşak/Ulubey/İnay lokasyonları uçucu yağ oranları bakımından önemli bir farklılık göstermemiş olup, bu lokasyonların değerleri aynı grupta yer almıştır (Çizelge 3). Bu durum da bize bu üç lokasyonun ekolojik koşullarının birbirlerinden çok farklı olmadığını göstermektedir. Aksine Isparta/Keçiborlu/Kuyucak lokasyonunun diğer lokasyonlardan hem iklim ve hem de toprak koşulları bakımından farklı olduğu görülmektedir. En yüksek uçucu yağ değerinin elde edildiği ısparta ilinde bitki hasadının yapıldığı temmuz yayında yağış miktarının düşük olmasına karşılık sıcaklığın yüksek olması yüksek uçucu yağ oranının elde edilmesinde etkili olmuştur. Aynı şekilde toprak koşullarının da diğer illere 
kıyasla Isparta ilinde daha olumsuz olması özellikle kireç ve tuz oranının yüksekliği ve organik madde içeriği bakımından da yetersiz olması uçucu yağ oranının yükselmesinde etkili olduğu düşünülmektedir.

Çizelge 3. Farklı lokasyonlara göre Lavandula x intermedia türüne ait uçucu yağ oranları (\%).

Table 3. The effect of different location factor on average values of essential oil content of lavandin (\%).

\begin{tabular}{lc}
\hline Lokasyon & Uçucu yağ oranı (\%) \\
\hline Afyon & $5.93 \mathrm{~b}$ \\
Eskişehir & $5.63 \mathrm{~b}$ \\
Isparta & $7.80 \mathrm{a}$ \\
Uşak & $6.57 \mathrm{~b}$ \\
Ortalama & 6.48 \\
F değeri (lokasyon) & $24.46^{* *}$ \\
CV (\%) & 14.32 \\
\hline
\end{tabular}

${ }^{\star} \mathrm{p}<0.05 ;{ }^{* \star} \mathrm{p}<0.01$; öd önemli değil.

Bilindiği gibi ekolojik koşulları oluşturan iklim ve toprak koşulları lokasyonlara bağlı olarak değişiklik göstermektedir. İklimin en önemli unsurları olan sıcaklık, yağış, hava nispi nemi, ışıklanma süresi, ışık yoğunluğu ve gece gündüz sıcaklık farkları lokasyonla birlikte değişim göstermektedir (Kevseroğlu, 2014). Aynı şekilde değişen lokasyona bağlı olarak toprağın fiziksel, kimyasal ve biyolojik özelliklerinde de değişim ortaya çıkmaktadır (Saeb ve Gholamrezaee, 2012). Bu çalışmada elde edilen uçucu yağ oranlarında lokasyonlara bağlı olarak ortaya çıkan farklııklar lokasyonlara bağlı olarak değişen ekolojik farklııklarla açıklanabilir (Turhan, 2006).

Çalışmada tespit edilen uçucu yağ oranları (\%5.63-7.80) benzer çalışmalarda aynı şekilde sapsız kuru çiçeklerde belirlenen uçucu yağ değerleri (\%5-6) ile paralellik göstermektedir (Erbaş ve Baydar 2008; Baydar, 2010). Uçucu yağ oranı olarak daha düşük değer belirten çalışmalarda (\%1.0-2.5) ise ya taze çiçekler ya da saplı kuru çiçeklerin kullanılmış olduğu görülmektedir (Kara ve Baydar, 2014; Karık ve ark., 2017; Erbaş ve Baydar 2008; Erbaş ve ark., 2017).

Aromatik bitkilerde üretilen uçucu yağların kullanım alanlarının belirlenmesinde ve dolayısıyla ürünün fiyatının belirlenmesinde uçucu yağın kimyasal içeriği büyük öneme sahiptir. Uçucu yağı ürün olarak piyasaya arz etmeyi planlayan üreticiler üretimlerinde kuru materyalin uçucu yağ oranına dikkat etmeleri gerektiği gibi uçucu yağın kimyasal kompozisyonunda da pazarın talebini dikkate almak zorundadır. Aksi takdirde üretilen ürünün ticari değerini yitireceğini bilmeleri gerekmektedir. Lavandin bitkisinden farklı şekillerde yararlanılmaktadır. Kullanım alanlarından en önemlisi ise elde edilen uçucu yağın parfüm endüstrisinde değerlendirilmesidir. Fakat üretilen uçucu yağların bu sektörde uygun fiyatla değerlendirilmesi için Avrupa farmakopesinde belirtildiği gibi uçucu yağın linalil asetat oranı en az \%35 ve kafur oranının da en fazla \%1.2 olması istenmektedir (Karık ve ark., 2017). Ayrıca, ISO 3515:2002 standardına göre lavanta uçucu yağında linalool ve linalil asetatın \% $25^{\prime}$ in üzerinde olması, kafur ve limonenin \%0.5'in altında olması, terpinen 4-ol'un \%2-6 arasında olması ve $\alpha$-terpinen'in ise \%1'den az olması istenmektedir (Kara ve Baydar, 2014).

Çalışmada dört farkıı lokasyondan elde edilen uçucu yağ örneklerinin kimyasal kompozisyonları Çizelge 4'te verilmiştir. Uçucu yağ örneklerinde yapılan analizlerde örneklerin 40 farklı bileşeni içerdiği tespit edilmiştir. Farklı lokasyonlara ait uçucu yağ örneklerinde linalool oranı \%41.34-53.10 arasında değişim göstermiştir. En yüksek linalool oranı Eskişehir lokasyonunda tespit edilirken, en düşük linalool oranı ise Uşak lokasyonunda tespit edilmiştir. Afyon ve Isparta lokasyonlarının örneklerinde ise linalool oranları sırasıyla \%51.10 ve \%48.84 olarak belirlenmiştir. Çalışmadan elde edilen değerlere göre linalool oranının lokasyonlara bağlı olarak \%11.69 oranında bir değişim gösterdiği tespit edilmiştir. Lavanta uçucu yağının bir diğer önemli bileşeni olan linalil asetat oranı ise lokasyonlara bağlı olarak \%1.83-23.54 arasında değişim gösterdiği belirlenmiştir. En yüksek linalil asetat oranı Isparta lokasyonundan elde edilirken, en düşük oran ise Eskişehir lokasyonundan elde edilmiştir. Linalil asetat oranı bakımından diğer iki lokasyon incelendiğinde Uşak lokasyonu \%21.58 değeri ile Isparta lokasyonuna daha yakın iken, Afyon lokasyonu ise \%3.14 değeri ile Eskişehir lokasyonuna daha yakın durum sergilemiştir. Linalil asetat ve linalool oranlarıın toplamı \%54.24-72.38 arasında değişim göstermiştir. İki bileşenin toplamı olarak en yüksek değer Isparta lokasyonunda tespit edilirken, en düşük değer ise Afyon lokasyonundan elde edilmiştir. Linalil asetat ve linalool oranlarının toplamı Eskişehir lokasyonunda \%54.93 iken, Uşak lokasyonunda ise \%62.92 olarak belirlenmiştir.

Isparta ve Uşak lokasyonlarının uçucu yağ örneklerinde terpinen 4-ol tespit edilemezken, Afyon lokasyonu örneklerinde \%9.84 ve Eskişehir lokasyonu örneklerinde ise \%12.09 oranlarında tespit edilmiştir. Lokasyonların uçucu yağ örneklerinde ise kafur oranları \%4.48-7.60 arasında değişmiştir. En yüksek kafur oranı Afyon örneğinden elde edilirken, en düşük oran ise Isparta örneğinden elde edilmiştir. Eskişehir ve Uşak örneklerinde ise kafur oranları \%6.22 ve \%6.65 olarak belirlenmiştir. Kalite açısından bir diğer önemli bileşen olan limonen bakımından 
lokasyonlar incelendiğinde \%0.53-1.13 arasında değiştiği görülmüştür. En yüksek limonen Afyon örneğinde belirlenirken, en düşük değer ise Isparta örneğinde belirlenmiştir.

Çizelge 4. Farklı lokasyonlara göre Lavandula x intermedia türüne ait uçucu yağ bileşenleri (\%). Table 4. The effect of different location factor on essential oil composition of lavandin (\%).

\begin{tabular}{|c|c|c|c|c|c|c|}
\hline Sira No & R.Time & Uçucu Yağ Bileşenleri & Afyon & Eskişehir & Isparta & Uşak \\
\hline 1 & 11.15 & $\alpha$-Pinene & 0.49 & 0.47 & - & - \\
\hline 2 & 12.82 & Campene & 0.39 & 0.35 & - & 0.27 \\
\hline 3 & 16.90 & $\beta$-Myrcene & 0.54 & 0.37 & 0.82 & 0.81 \\
\hline 4 & 18.54 & Limonene & 1.13 & 0.96 & 0.53 & 0.80 \\
\hline 5 & 19.03 & 1.8-Cineole & 4.94 & 3.17 & 1.95 & 6.27 \\
\hline 6 & 20.01 & cis-Ocimene & 2.72 & 1.24 & 1.06 & 0.85 \\
\hline 7 & 20.53 & $\gamma$-Terpinene & 0.23 & 0.21 & - & - \\
\hline 8 & 20.76 & $\beta$-Ocimene & 0.51 & 0.53 & 2.44 & 1.21 \\
\hline 9 & 21.05 & 3-Octanone & - & 0.24 & 0.71 & 0.73 \\
\hline 10 & 21.66 & o-Cymene & 0.14 & 0.15 & - & - \\
\hline 11 & 21.68 & n-Hexyl acetate & 0.26 & 0.48 & 0.74 & 0.62 \\
\hline 12 & 22.09 & $\alpha$-Terpinolene & 0.29 & 0.23 & 0.27 & 0.25 \\
\hline 13 & 24.53 & Hexyl isobutyrate & 0.29 & - & - & 0.56 \\
\hline 14 & 24.78 & n-Hexanol & 0.36 & 0.54 & - & - \\
\hline 15 & 27.30 & Hexyl butanoate & 0.76 & 0.97 & 1.27 & - \\
\hline 16 & 27.74 & Hexyl 2-methylbutanoate & 0.45 & 0.34 & - & - \\
\hline 17 & 29.07 & Trans-Sabinene hydrate & 0.35 & 0.44 & - & - \\
\hline 18 & 29.34 & Linalool oxide & - & 0.33 & - & - \\
\hline 19 & 31.16 & Camphor & 7.60 & 6.22 & 4.48 & 6.65 \\
\hline 20 & 31.68 & Linalool & 51.10 & 53.10 & 48.84 & 41.34 \\
\hline 21 & 31.92 & cis-sabinene hydrate & 0.45 & 0.59 & - & - \\
\hline 22 & 32.06 & Linalyl acetate & 3.14 & 1.83 & 23.54 & 21.58 \\
\hline 23 & 33.55 & Lavandulyl acetate & - & - & - & 2.47 \\
\hline 24 & 33.62 & $\beta$-Caryophyllene & - & - & 2.04 & - \\
\hline 25 & 33.67 & Terpinene-4-ol & 9.85 & 12.09 & - & - \\
\hline 26 & 33.79 & Hexyl hexanoate & 0.21 & 0.27 & - & - \\
\hline 27 & 34.17 & Hexyl tiglate & 0.19 & - & 0.27 & - \\
\hline 28 & 35.37 & (Z)- $\beta$-Farnesene & 1.78 & 1.01 & 0.44 & 0.30 \\
\hline 29 & 35.64 & Lavandulol & 1.11 & 1.30 & - & - \\
\hline 30 & 36.19 & Cryptone & 0.33 & - & - & 0.41 \\
\hline 31 & 36.44 & $\alpha$-Terpineol & 0.48 & 0.45 & 2.96 & 3.30 \\
\hline 32 & 36.56 & Borneol & 7.22 & 9.41 & 1.79 & 3.35 \\
\hline 33 & 37.04 & Germacrene D & 0.25 & - & - & - \\
\hline 34 & 38.07 & Neryl acetate & - & 0.33 & 0.70 & 0.71 \\
\hline 35 & 38.07 & Geranyl acetate & 0.49 & - & 1.25 & 1.28 \\
\hline 36 & 39.14 & Nerol & - & - & 0.60 & 0.84 \\
\hline 37 & 40.35 & Geraniol & 0.23 & 0.20 & 1.63 & 1.78 \\
\hline 38 & 44.57 & Caryophyllene oxide & - & - & - & 0.27 \\
\hline 39 & 49.32 & Carvacrol & 0.30 & 0.85 & 0.86 & 1.92 \\
\hline \multirow[t]{2}{*}{40} & 49.62 & $\alpha$-Bisabolol & 0.48 & 0.34 & 0.85 & 1.08 \\
\hline & & Tanımlanamayan & 0.93 & 0.99 & - & 0.35 \\
\hline
\end{tabular}

Borneol oranı ise lokasyonlara bağlı olarak \%1.79-9.41 arasında değişmiştir. En yüksek borneol değeri Eskişehir örneğinde en düşük borneol değeri ise Isparta örneğinde belirlenmiştir. 1,8-Sineol değişimi lokasyonlara bağlı 
olarak \%1.95-6.27 arasında olmuştur. En düşük değer Isparta örneğinde tespit edilirken, en yüksek değer ise Uşak örneğinde tespit edilmiştir. $\alpha$-terpineol içerikleri bakımından lokasyon örnekleri incelendiğinde değerlerin \%0.453.30 arasında değiştiği belirlenmiştir. En yüksek değer Uşak örneğinde, en düşük değer ise Eskişehir örneğinde belirlenmiştir. Lokasyonlara ait örneklerde $\beta$-caryophyllen (\%2.04) sadece Isparta lokasyonunda tespit edilmiştir. Bunların dışında, Isparta örneğinin uçucu yağında geranil asetat (\%1.25), geraniol (\%1.63), hexyl butanoat (\%1.27), cis-Ocimen (\%1.06) ve $\beta$-Ocimene (\%2.44) tespit edilmiştir.

Çalışmada incelenen lokasyonların uçucu yağ kompozisyonu üzerinde etkili olduğu elde edilen değerlerden anlaşılmıştır. Bu durum bize uçucu yağ kompozisyonu üzerinde lokasyonlara bağlı olarak değişen ekolojik koşulların etkisini göstermektedir. Değişen sıcaklık, yağış miktarı, hava nispi nemi, ışıklanma durumu ve rakım uçucu yağın kimyasal kompozisyonunda varyasyona neden olmuştur (Biesiada ve ark., 2008; Kara ve Baydar, 2014; Mammadov, 2014, Karık ve ark., 2017; Erbaş ve ark., 2017; Sönmez ve ark., 2018). Uçucu yağ örneklerinde belirlenmiş olan ana bileşenler bakımından değerlerimiz Baydar (2010), Erbaş ve Baydar (2008) ve Woronuk ve ark. (2011) bildirdikleri değerlerle paralellik göstermiştir.

\section{SONUÇ}

Bu çalışma kapsamında, değişen lokasyonlara bağlı olarak incelenen uçucu yağ oranları ve uçucu yağların kimyasal komposizyonu birlikte değerlendirildiğinde hem uçucu yağ oranı hem de uçucu yağ kompozisyonu bakımından lavandin yağı üretimi için en uygun lokasyonun Isparta olduğu görülmüştür. Çünkü Isparta lokasyonunda bir taraftan en yüksek uçucu yağ oranına sahip kuru çiçekler üretilirken, diğer taraftan da yüksek linalool ve linalil asetata sahip uçucu yağ üretilmiştir. Ayrıca lavanta yağı kalitesi açısından önemli olan kafur ve limonen oranını da en düşük düzeyde içeren yağlar Isparta örneğinden elde edilmiştir.

\section{ÇIKAR ÇATIŞMASI}

Yazarlar arasında herhangi bir çıkar çatışması mevcut değildir.

\section{YAZAR KATKISI}

Duran Katar: Arazi ve laboratuvar çalışmalarının yürütülmesi, makalenin yazılması.

Mustafa Can: Arazi ve laboratuvar çalışmalarının gerçekleştirilmesi, istatistik analizinin yapılması.

Nimet Katar: Arazi ve laboratuvar çalışmalarının gerçekleştirilmesi.

\section{KAYNAKLAR}

Baser, K. H. C. (1993). Essential oils of anatolian lamiaceae: a profile. Acta Horticulture, 333, 217-238.

Baydar, H. (2010). Beyoğlu'na lavanta Isparta'dan gitmelidir. Tarım Aktüel Dergisi, 15, 62-63.

Baydar, H., Kazaz, S., \& Erbaş, S. (2013). Yağ gülü (Rosa damascena Mill.)'nde morfogenetik, ontogenetik ve diurnal varyabiliteler. Süleyman Demirel Üniversitesi Ziraat Fakültesi Dergisi, 8(1), 1-11.

Baydar, H. (2013). Tıbbi, Aromatik ve Keyf Bitkileri Bilimi ve Teknolojisi. Süleyman Demirel Üniversitesi Yayınları, Yayın No:51, Isparta.

Beus, C. (2006). Growing and Marketing Lavender. Washington State University, 28p, Washington.

Biesiada, A., Sokół-Łetowska, A., \& Kucharska, A. (2008). The effect of nitrogen fertilization on yielding and antioxidant activity of lavender (Lavandula angustifolia Mill.). Acta Scientiarum Polonorum Hortorum Cultus, 7(2), 33-40.

Dudas, S., Segon, P., Erhatic, R., \& Kovacevic, V. (2013). Influence of drying temperatures on essential oil content in savory Satureja montana L. (Lamiaceae). 2nd Scientific Conference with International Participation $24^{\text {th }}-25^{\text {th }}$, Biotechnical Centre Naklo, Strahinj 99, Naklo, Slovenia.

Erbaş, S. \& Baydar, H. (2008). Effect of harvest time and drying temperature on essential oil content and composition in lavandin (Lavandula $\times$ intermedia Emeric ex Loisel.). Turkish Journal of Field Crops, 13(1): 24-31.

Erbaş, S., Kucukyumuk, Z., Baydar, H., Erdal, İ., \& Şanlı, A. (2017). Effects of different phosphorus doses on nutrient concentrations as well as yield and quality characteristics of lavandin (Lavandula $\times$ intermedia Emeric ex Loisel. var. Super). Turkish Journal of Field Crops, 22(1), 32-38. 
Katar ve ark., Farklı Lokasyonların Lavandin (Lavandula x intermedia Emeric ex Loisel.)'de Uçucu Yağ Oranı ve Kimyasal Kompozisyonu Üzerine Etkisi

Gülşen, O. (2017). Yozgat ili Çayıralan Illçesinde Lavanta Yetiştiriciliğini Geliştirme Projesi Sonuç Raporu. Orta Anadolu Kalkınma Ajansı, S: 31, Kayseri.

Hui, L., He, L., Huan, L., XiaoLan, L., \& Aiguo, Z. (2010). Chemical composition of lavender essential oil and its antioxidant activity and inhibition against rhinitis related bacteria. African Journal Microbiology Research, 4(4), 309-313.

Kara, M. Ş., Özkutlu, F., Açıkgöz, M. A., \& Batı, E. (2014). Essential macro nutrient profiles of selected medicinal and aromatic plants from the family of lamiaceae. Proceedings of the Eighth Conference on Medicinal and Aromatic Plants of Southeast European Countries (8th CMAPSEEC), Durrës, Albania.

Kara, N. \& Baydar, H. (2014). Kuruma yöntemleri, depolama koşulları ve sürelerinin lavanta (lavandula spp.)'nın uçucu yağ oranı ve bileşenlerine etkisi. Yüzüncü Yıl Üniversitesi Tarım Bilimleri Dergisi, 24(2), 185-192.

Karık, Ü., Çiçek, F., \& Çınar, O. (2017). Menemen ekolojik koşullarında lavanta (lavandula spp.) tür ve çeşitlerinin morfolojik, verim kalite özelliklerinin belirlenmesi. Anadolu Ege Tarımsal Araştırma Enstitüsü Dergisi, 27(1), 17-28.

Katar, N., Katar, D., Aydın, D., \& Olgun, M. (2018). Tıbbi adaçayı (salvia officinalis I.)'nda uçucu yağ oranı ve kompozisyonu üzerine ontogenetik varyabilitenin etkisi. Uluslararası Tarım ve Yaban Hayatı Bilimleri Dergisi, 4(2), $231-236$.

Katar, N., Katar, D., Temel, R., Karakurt, S., Bolatkıran, İ., Yıldız, E., \& Soltanbeigi, A. (2019). The effect of different harvest dates on the yield and quality properties of rosemary (Rosmarinus officinalis L.) plant. Biological Diversity and Conservation, 12(3), 7-13.

Katar, N. \& Aytaç, Z. (2019). Sater (Satureja hortensis L.) genotiplerinin farklı lokasyonlarda agronomik ve kalite özelliklerinin belirlenmesi. Ziraat Fakültesi Dergisi, 14(2), 253-269.

Kevseroğlu, K. (2014). Bitki Ekolojisi. Ondokuz Mayıs Üniversitesi Ziraat Fakültesi Yayınları, Yayın No: 31, Samsun.

Mammadov, R. (2014). Tohumlu Bitkilerde Sekonder Metabolitler. Nobel Akademik Yayıncllık, Yayın No: 841, Ankara.

Mumivand, H., Babalar, M., Hadian, J., \& Fakhr-Tabatabaei, M. (2011). Plant growth and essential oil content and composition of Satureja hortensis L. CV. Saturn in response to calcium carbonate and nitrogen application rates. Journal of Medicinal Plants Research, 5(10), 1859-1866.

Saeb, K., \& Gholamrezaee, S. (2012). Variation of essential oil composition of Melissa officinalis L. leaves during different stages of plant growth. Asian Pacific Journal of Tropical Biomedicine, 2(2), 547-549.

Sönmez, Ç., Şimşek Soysal, A. Ö., Okkaoğlu, H., Karık, Ü., Taghiloofar, A. H., \& Bayram, E. (2018). Determination of some yield and quality characteristics among individual plants of lavender (Lavandula angustifolia mill.) populations grown under mediterranean conditions in Turkey. Pakistan Journal of Botany, 50(6): 2285-2290.

Telci, İ. (2005). Reyhan (Ocimum basilicum L.) genotiplerinde uygun biçim yüksekliklerinin belirlenmesi. Gaziosmanpaşa Üniversitesi Ziraat Fakültesi Dergisi, 22(2), 77-83.

Telci, I.., Bayram, E., Yılmaz, G., \& Avcl, B. (2006). Variability in essential oil composition of turkish basils (Ocimum basilicum L.). Biochemical Systematics and Ecology, 34, 489-497.

Turhan, H. (2006). Handbook of Herbs and Spices (Vol. 3). Lemon Balm (Chapter 23). Woodhead Publishing, England.

Tursun, A. O., \& Telci, İ. (2020). The effects of carbon dioxide and temperature on essential oil composition of purple basil (Ocimum basilicum L.). Journal of Essential Oil Bearing Plants, 22(2), 255-265.

Whiriskey, J., \& McCarthy, P. (2006). Lavender production. https://www.teagasc.ie/LavenderProduction.pdf. Access date : April $24,2020$.

Woronuk, G., Demissie, Z., Rheault, M., \& Mahmoud, S. (2011). Biosynthesis and therapeutic properties of lavandula essential oil constituents. Planta Medica, 77(1), 7-15. 